\title{
ANÁLISIS DE LOS TEXTOS ESCOLARES DE HISTORIA. ESTUDIO DE CASO SOBRE LA POSGUERRA CIVIL ESPAÑOLA
}

\author{
Enrique Javier Díez Gutiérrez ${ }^{12}$ \\ Universidad de León-España \\ enrique.diez@unileon.es
}

Recepción: 14/04/2011

Evaluación: 09/05/2011

Aceptación: 22/06/2011

Artículo de Reflexión

\section{RESUMEN}

El objetivo ha sido analizar los libros de texto de la asignatura de Historia. Más concretamente, hemos querido analizar los contenidos que se reflejan actualmente en los contenidos de los libros de texto escolares sobre el período correspondiente a la historia de España, que se ocupa de la posguerra a partir de 1939 y, especialmente, de la represión de la dictadura franquista y la lucha antifranquista que se prolongó hasta bien entrados los 60. Los contenidos correspondientes a este período histórico están ubicados curricularmente sobre todo en los cursos correspondientes a las edades de 15 años y de 17 años. La metodología utilizada es de corte cualitativo, usando como instrumentos de investigación el análisis crítico de contenido y las entrevistas al profesorado. Tras este extenso estudio nos hemos encontrado que en los libros de texto de Historia se sigue ignorando u ocultando buena parte de los hechos que se desarrollaron tras el fracaso de la experiencia republicana en los años 30 en España, especialmente los relacionados con la represión de la dictadura franquista y la resistencia de muchos

\footnotetext{
${ }^{1}$ Doctor en Ciencias de la Educación, profesor titular de la Universidad de León (España). Licenciado en Filosofía. Diplomado en Trabajo Social y Educación Social. Especialista en organización educativa, actualmente desarrolla su labor docente e investigadora en el campo de la educación intercultural, el género y la política educativa. ${ }^{2}$ En este artículo se describe la investigación que hemos realizado a lo largo de tres años, desde la Universidad de León (España) en colaboración con el Foro por la Memoria de León.
} 
hombres y mujeres frente a ella. Las conclusiones de esta investigación parecen recordar lo que decía el escritor argentino y víctima de su dictadura militar, Juan Gelman: "Desaparecen los dictadores y aparecen inmediatamente los organizadores del olvido".

Palabras clave: Revista Historia de la Educación Latinoamericana, textos escolares, memoria histórica, historia de España, análisis de contenido, dictadura franquista, lucha antifranquista.

\title{
ANALYSIS OF SCHOLAR HISTORY TEXTBOOKS- CASE STUDY ON SPANISH CIVIL POST WAR
}

\author{
Enrique Javier Díez Gutiérrez \\ Universidad de León - España \\ enrique.diez@unileon.es
}

\begin{abstract}
The objective has been analyzing the text in History subject, specifically, analyzing the contents that are nowadays reflected on scholar textbooks in a specific history period of time of Spain, taking place in the Post war since 1939. The Franco Dictatorship Repression and Franco fight lasted begining the 60s. The corresponding contents at this period are located curricularly on the corresponding courses between 15 and 17 years old. The methodology used was qualitative using research instruments from the critical analysis of content and the teachers ' interviews. After having done this lengthy study, we have found that thte History textbooks keep on ignoring or hiding facts that were developed after Republican failure experience in the 30s in Spain, specially the ones related to the Franco Dictatorship Repression and the resistance of many men and women in front of her. The findings of this research seem to remember what the Argentian writerJuan Gelman, victim of military didactorship, said: "The dictators dissapear and the organizers of oversight inmediately appear".
\end{abstract}

Key words: Journal of Latin American Education History, school textbooks, bistorical memory, Spanish history, content analysis, franco dictatorshi, franco fight. 


\title{
ANÁLISE DOS TEXTOS ESCOLARES DE HISTORIA. ESTUDO DE CASO SOBRE O PÓS-GUERRA CIVIL NA ESPANHA
}

\author{
Enrique Javier Díez Gutiérrez \\ Universidade de León - Espanba \\ enrique.dię@unileon.es
}

\begin{abstract}
RESUMO
O objetivo desta pesquisa foi analisar os livros de texto da disciplina de História. Mais concretamente, quisemos analisar os conteúdos que se refletem atualmente nos conteúdos dos livros de textos escolares sobre o período correspondente à história da Espanha, que se ocupa do pós-guerra a partir de 1939 e, especialmente da história da ditadura franquista e a luta anti-franquista que se estendeu até meados dos anos 60. Os conteúdos correspondentes a esse período histórico estão localizados curricularmente em todos os cursos correspondentes às idades de 15 e de 17 anos. A metodologia utilizada é de corte qualitativo, usando como instrumentos de pesquisa a análise crítica de conteúdo as entrevistas ao professorado. Neste extenso estudo percebemos que nos livros de texto de História segue-se ignorando ou ocultando boa parte dos fatos que se desenvolveram no fracasso da experiência republicana dos anos 30 na Espanha, especialmente os relacionados com a repressão da ditadura franquista e a sua resistência por parte de muitos homens e mulheres. As conclusões desta pesquisa parecem recordar o que dizia o escritor argentino e vítima de sua ditadura militar, Juan Gelman: "Desaparecem os ditadores e aparecem imediatamente os organizados do esquecimento".
\end{abstract}

Palavras-chave: Revista História da Educação Latino-americana, textos escolares, memória histórica, bistória da Espanba, análise de conteúdo, ditadura franquista, luta anti-franquista. 


\section{INTRODUCCIÓN}

La importancia de los contenidos de los libros de texto de Historia. El estudio de la Historia es reconocido como un elemento fundamental de la actividad escolar por su valor formativo al referirse al estudio de la experiencia humana a través del tiempo. El pasado conforma muchos de los esquemas de conocimiento e interpretación de la realidad al estar presente en nuestra vida actual, tanto individual como colectiva. La perspectiva temporal y el enfoque globalizador, específicos de esta disciplina, proporciona conocimientos relevantes sobre ese pasado que ayudan a la comprensión de la realidad actual. A su vez, contribuye a mejorar la percepción del entorno social, a construir una memoria colectiva y a la formación de ciudadanos y ciudadanas responsables y conscientes de sus derechos y de sus obligaciones para con la sociedad. Su estudio, que parte de los conocimientos adquiridos en etapas educativas anteriores, debe servir para profundizar en el conocimiento de su herencia personal y colectiva.

El material fundamental para el estudio de la Historia son los manuales escolares. Los textos escolares dominan el currículum ${ }^{3}$. Cerca del 90\% del tiempo escolar en las escuelas españolas se centra en torno a ellos, tanto del alumnado como del profesorado. De ahí su importancia: ayudan a construir el imaginario colectivo de las futuras generaciones. Los enseñantes tienden a considerar los contenidos de los libros de texto como algo que no debe ser sometido a crítica, al contrario, encuentra en ellos seguridad y garantía de buen hacer profesional. Respecto a los contenidos se busca objetividad y concreción, por lo que los libros de texto son mejor valorados cuanto más se acercan a esta concepción técnica de la enseñanza que entiende el saber como algo acabado, objetivo y no sometido a revisión crítica. Sin embargo, desde un enfoque crítico, es manifiesto que todos los contenidos científicos o escolares son provisionales, en constante discusión y cargados de la ideología que subyace a sus impulsores y al contexto histórico y social de su producción. Más aún, en el caso de los contenidos históricos, siempre sometidos a cuestionamiento y revisión.

3 APPLE, M. W. (1986): Maestros y textos. Una economía política de las relaciones de clase y sexo en educación. Barcelona, Paidós-MEC. 


\section{El origen de la investigación}

Este proyecto surgió a partir de la participación, de parte del equipo de investigación, en la producción y montaje del documental "Los campos del silencio", dirigido por la directora de cine española Eloina Terrón, sobre los presos republicanos en campos de concentración franquistas. En la última parte del mismo se grababa en un Instituto de Secundaria a un grupo de alumnado preguntándole sobre el campo de concentración que había estado ubicado en su pueblo, en el que hubo un batallón de unos 250 presos republicanos, de 1939 a 1947, para trabajar como “esclavos" para una empresa privada (Minas Moro) en la extracción de carbón en las minas del Bierzo (una zona del norte de León en España). El documental se centraba en los mecanismos de construcción social de la inconsciencia colectiva, de ese silencio, miedo y olvido que aún hoy en día se puede sentir en donde ocurrieron los hechos y donde viven los descendientes de muchos de aquellos presos.

En su realización nos dimos cuenta que los alumnos y alumnas del Instituto de Secundaria de Fabero del Bierzo (León) no sabían que en su propio pueblo hubo uno de estos campos de trabajo forzado. Realmente, cuando indagamos más, nos sorprendió que ni siquiera supieran que algunos de sus abuelos habían estado ahí presos y que sus abuelas y todos los familiares de estos presos habían sufrido la represión franquista, con el fin de "buscar una solución justa y cristiana al gravísimo problema de la delincuencia roja" tal como aparece en las Memorias de la Redención de Penas de la Biblioteca de la Dirección General de Instituciones penitenciarias del año $39^{4}$. Cuando fuimos con estos alumnos y alumnas de bachillerato al sitio donde había estado el campo de concentración y se les explicó lo que allí había pasado y lo que esto supuso, así como la lucha que una parte de sus mayores había seguido librando contra el franquismo, se produjo una especie de conmoción ante la sensación de que se les había ocultado buena parte de su propia historia.

De esta experiencia surgió el proyecto de analizar los contenidos que sobre esta época se estaban dando en las clases de historia a nuestro alumnado, los materiales curriculares que estaba empleando el profesorado y los conocimientos que realmente estaban aprendiendo.

${ }^{4}$ DIRECCIÓN GENERAL DE INSTITUCIONES PENITENCIARIAS. (1939):

Memorias de la Redención de Penas. Madrid, Ministerio de Guerra. 
Así se inició el trabajo de investigación desde la Universidad de León en colaboración con la Asociación "Foro por la Memoria de León".

\section{El objetivo de la investigación}

La investigación se ha centrado en el análisis de los contenidos de los libros de texto de la asignatura de Historia. Más concretamente, el período correspondiente a la historia de España que se ocupan de la posguerra y especialmente de la represión de la dictadura franquista y la lucha antifranquista que se prolongó hasta bien entrados los 60 . Hemos querido analizar los contenidos que sobre esta época se están dando en las clases de historia a nuestro alumnado, los materiales curriculares que emplea el profesorado y los conocimientos que realmente aprenden los estudiantes sobre esta parte de la historia. Analizar cómo se refleja actualmente en los contenidos de los libros de texto escolares la represión franquista y la lucha antifranquista.

Nos hemos pasado tres años revisando buena parte de los libros de texto españoles, desde primaria hasta bachillerato, para analizar cómo transmiten no sólo los datos y acontecimientos sobre el período destinado a la II República, sino especialmente los contenidos, actividades e ilustraciones dedicados a la represión franquista y a la lucha antifranquista tras la guerra civil. Nos centramos más en los libros de historia de segundo de bachillerato, puesto que es el curso donde más se desarrolla y estudia este período histórico, según el currículum oficial vigente. Pero también exploramos los contenidos de cuarto de la educación secundaria obligatoria, dirigidos a alumnado de entre quince y dieciséis años, donde también se exponen de forma genérica los acontecimientos más importantes de este período, para analizar el enfoque y extensión que se le daba a los mismos. Lógicamente, en primaria, dada la generalidad y escasez con la que se abordan estos contenidos, ligados a una visión relacionada con otros aspectos sociales y culturales, era más difícil hacer un análisis en profundidad, pero constatamos que ya se intuye la orientación que va a predominar en los cursos superiores sobre estos temas. 
En definitiva, la pretensión de esta investigación se ha enfocado al:

a) Estudio de los materiales curriculares y libros de texto que utiliza el alumnado, especialmente en Educación Secundaria Obligatoria y Bachillerato (de 12 a 18 años) de todo el Estado español para analizar los contenidos que en ellos aparecen sobre las consecuencias de la guerra civil, la represión franquista y la lucha antifranquista, indagando sobre su extensión, orientación, completud y visión, en varias dimensiones:

- La proporción destinada a este período histórico en relación con el destinado a otros períodos de la historia de España.

- Los aspectos resaltados y destacados, frente a aquellos silenciados u ocultados.

- La visión que se plantea en los mismos sobre las víctimas de la guerra civil y del franquismo.

b) Se analizan también aquellos documentos textuales, gráficos, materiales visuales y auditivos que se están utilizando como materiales didácticos complementarios en los centros educativos relacionados con la represión y resistencia de las víctimas de la guerra civil y del franquismo.

Se está haciendo una investigación complementaria con el profesorado de historia de Secundaria y Bachillerato sobre su percepción respecto a la adecuación de los contenidos en los libros de texto y materiales curriculares complementarios que tratan el período de la guerra civil, las víctimas de la misma y del franquismo y la lucha antifranquista.

\section{Metodología}

La investigación en el campo de las ciencias sociales tiene unas características propias que la hacen diferente a la investigación en ciencias naturales. La peculiaridad de los fenómenos que estudia, obligan a utilizar diferentes métodos en su investigación. Los procesos educativos son complejos. Intervienen en ellos multitud de factores interrelacionados cuyo aislamiento sólo puede conseguir la distorsión del conocimiento pretendido. A veces ese afán por mantener un supuesto "rigor" en la 
investigación nos conduce a la selección, consciente o inconscientemente, de las variables más fácilmente cuantificables u operativas, con el doble peligro, por un lado, de tomar en consideración los aspectos menos relevantes, los más nimios, los de menos interés educativo y, por otro, consecuencia del primero, llegar a conclusiones sesgadas, erróneas y engañosas ${ }^{5}$. Pero hay un mayor peligro. Desde la perspectiva cuantitativa, se tiende a suprimir de la investigación todo aquello que no va a ser medido, es decir, lo difícilmente cuantificable, o al menos se relega a un segundo plano en la práctica.

La complejidad de los fenómenos educativos es de tal magnitud que difícilmente pueden ser investigados a través de mediciones. Cuando en aras de una supuesta 'mayor cientificidad', diseccionamos la realidad, descontextualizamos los fenómenos educativos y les atribuimos valores numéricos, a fin de adaptarlos a una metodología cuantitativa, es fácil que hayamos forjado una imagen de esa realidad irreconocible por los que en ella están inmersos y, por tanto, incapaz de producir conocimiento válido para la comprensión, la reflexión y la mejora de la intervención educativa o social.

Por eso en la fase de investigación propiamente dicha, se ha utilizado una metodología fundamentalmente cualitativa y etnográfica, puesto que se trata de analizar, comprender y explicar fenómenos educativos . No obstante, aunque nuestra opción es de tipo fundamentalmente cualitativo, siguiendo la propuesta de Cook y Reichardt, creemos que es necesario superar la falsa disyuntiva o enfrentamiento entre la utilización de métodos cuantitativos (aquéllos que buscan a través de los criterios de medida datos cuantificables y medibles en porcentajes) y métodos cualitativos (aquellos que buscan la información que subyace a la realidad y a los fenómenos y los procesos, y de los criterios que la configuran, y que ayudan a analizarla, comprenderla y conocerla mejor para su intervención). La negociación entre ambas metodologías es lo que se ha venido a llamar "triangulación"

\footnotetext{
${ }_{6}^{5}$ VAN MAANEN, J. (1983): Qualitative methodology. Beverly Hills, CA, Sage Publications. ${ }^{6}$ FERNÁNDEZ SIERRA, J. y SANTOS GUERRA, M. A. (1992): Evaluación cualitativa de programas de educación para la salud: Una experiencia hospitalaria. Málaga, Aljibe, p. 23. VELASCO, M. y DÍAZ DE RADA, A. (1997): La lógica de la investigación etnográfica. Madrid, Nona, p. 23.

${ }^{8}$ COOK, T. D. y REICHARDT, CH. S. (1986): Métodos cualitativos y cuantitativos en investigación evaluativa. Madrid, Morata. p. 67.
} 
cualitativa haya sido completada con algunos datos de corte cuantitativo en la entrevista semiestructurada, para complementar la información, orientados a recoger algunos aspectos sobre la situación de cada centro. Creemos que ambas metodologías son dos formas de aproximación a una misma realidad que, más que excluirse, llegan a integrarse, progresando cada una gracias a la otra, pues las aportaciones de una complementan las posibles carencias de la otra.

Para ello se han utilizado dos técnicas: las entrevistas a profesorado y el análisis crítico de contenido de libros de texto ${ }^{9}$. Se ha diseñado una entrevista para conocer la percepción que tiene el profesorado de Historia de ESO y Bachillerato respecto a la adecuación de los contenidos relacionados con las consecuencias de la Guerra Civil, la represión franquista y la lucha antifranquista en los libros de texto y materiales curriculares complementarios, en cuanto a su completud, su extensión, su orientación y visión, así como si la proporción destinada a este período histórico en relación con el destinado a otros períodos de la historia de España es la adecuada y si es adecuada la visión que se plantea en los mismos sobre las víctimas de la guerra civil y del franquismo.

En cuanto al análisis crítico de contenido de los libros de texto, se han revisado los manuales de historia desde primaria hasta bachillerato, para analizar cómo transmitían no sólo los datos y acontecimientos sobre el período destinado a la II República, sino especialmente los contenidos, actividades e ilustraciones dedicados a la represión franquista y a la lucha antifranquista tras la guerra civil. Nos centramos más en los libros de historia de segundo de bachillerato, puesto que es el curso donde más se desarrolla y estudia este período histórico, según el currículum oficial vigente. Pero también exploramos los contenidos de cuarto de la educación secundaria obligatoria, dirigidos a alumnado de entre quince y dieciséis años, donde también se exponen de forma genérica los acontecimientos más importantes de este período, para analizar el enfoque y extensión que se le daba a los mismos. El objetivo del análisis crítico de contenido ha sido lograr la emergencia del sentido latente que subyace en los componentes semánticos y formales plasmados en los libros de texto escolares. La parte cuantitativa se ha centrado en los elementos cuantificables: los aspectos formales y el contenido manifiesto

${ }^{9}$ HOLSTI, O.R. (1969): Content analysis for the social sciences and bumanities. MA, Reading Addison-Wesley; KRIPPENDORF, K. (1990): Metodología de análisis de contenido. Teoría y práctica. Barcelona, Paidós, p. 56. 
no sólo de los textos propiamente dichos, sino también de las imágenes analizando situación, tamaños, proporciones, relación, etc. La parte cualitativa se ha centrado más en el contenido latente, desarrollando una labor propiamente interpretativa, no limitándonos pues a las estructuras textuales o icónicas, sino profundizando más allá en el análisis de los diversos significados, opiniones o ideologías que sustentan las mismas.

$\mathrm{El}$ análisis crítico de contenido toma prestados aspectos esenciales del enfoque del análisis crítico del discurso ${ }^{10}$ que analiza cómo la dominación se reproduce y se resiste con los discursos ". Este enfoque concibe el discurso, por un lado, como un producto "susceptible de revelar determinados contenidos subyacentes (visiones del mundo, opiniones, ideologías)" y, por el otro, como un instrumento "capaz de proyectar esos contenidos en las representaciones sociales o individuales de las personas". El interés principal del ACD proviene de esa doble funcionalidad atribuida al discurso. Si éste es visto como un producto y como un instrumento capaz de reflejar visiones sociales pero también de cambiarlas e incluso en algunas ocasiones de crearlas, la nota que define y diferencia este tipo de análisis de otros que se incluyen en este campo es la intención de desvelar las complicadas relaciones que se establecen entre las estructuras de poder, las ideologías y los discursos a través de los cuales se configuran los dos elementos anteriores.

\section{Resultados: El olvido escolar de la II República y de la barbarie franquista}

Tras este extenso estudio sobre los libros de texto escolares, nos hemos encontrado que buena parte de estos materiales curriculares no recogen con suficiente relevancia una parte significativa de los hechos que se desarrollaron tras el fracaso de la experiencia republicana en los años 30 en España, especialmente los relacionados con la represión de la dictadura franquista y la resistencia de muchos hombres y mujeres frente a ella. De hecho, tienden a permanecer ignorados, silenciados o tratados "como de puntillas".

\footnotetext{
${ }^{10}$ VAN DIJK, Teun A. (1997): Racismo y análisis crítico de los medios. Barcelona, Paidós, p. 78 .

FAIRCLOUGH, Norman. (1992): Discourse and Social Change. Cambridge, Polity Press, p. 58.
} 
Las conclusiones de esta investigación parecen recordar lo que decía el escritor argentino y víctima de su dictadura militar, Juan Gelman: "Desaparecen los dictadores y aparecen inmediatamente los organizadores del olvido" ". En definitiva, se sigue ignorando u ocultando, en los manuales de Historia de Secundaria y Bachillerato, bajo una maraña de tópicos, la represión del franquismo, el papel legitimador de la iglesia católica con la dictadura o el papel de quienes siguieron luchando contra la dictadura durante largos años.

En concreto hay muchos aspectos que se silencian expresamente. El vacío está, sobre todo, en lo que se refiere a la represión franquista y al papel de los hombres y mujeres que siguieron luchando y resistiendo contra la dictadura franquista hasta mediados de los años 60. La mayoría de los libros de texto se centran en detallar, extensa y pormenorizadamente, la guerra civil y las diferentes batallas que se sucedieron durante la contienda, pero la historia de la resistencia antifranquista sólo se trata de manera esporádica y, en todo caso, en algunos de los libros de texto publicados más recientemente. Es cierto que algunos hacen referencia a temas como los paseos ${ }^{13}$, pero las cunetas, las fosas y la represión sistemática y organizada de los sospechosos y de sus familias no están en la mayoría de los libros de textos. Además, hay temas especialmente "tabú", como las incautaciones de bienes o el enorme papel legitimador de la Iglesia, que no se tocan ni siquiera "colateralmente". En general, se habla de los "desmanes de ambos bandos" y la impresión general que queda, al final, supone una concepción simplista y en parte legitimadora, ligada a una visión de dos partes enfrentadas de las que ganó una que, lógicamente, se convirtió en la vencedora y, por lo tanto, administradora del nuevo régimen.

Por citar algunos ejemplos significativos en todos los cursos, podemos hacer referencia al libro de la editorial Edelvives, según el cual la guerra civil fue un "conflicto fratricida" originado como "consecuencia" del "caos de la II República". Según la editorial Santillana, fue una guerra que enfrentó a "dos bandos", tal y como

${ }_{13}^{12}$ GELMAN. (2008): Contra los comisarios del olvido. El País, Reportaje, 29/11/2008, p. 27.

${ }^{13}$ Paseo: Término eufemístico utilizado para referirse al apresamiento y conducción para su fusilamiento clandestino de quienes eran señalados como simpatizantes o colaboradores de la República. 
se lee en sus manuales de $2^{\circ}$ de bachillerato. En los libros de esta editorial dirigidos también a $2^{\circ}$ de Bachillerato se puede leer: "en los dos bandos hubo un fenómeno semejante: la voluntad de exterminar al adversario produjo un simultáneo terror". Incluso el propio currículo oficial de Historia de España, de $2^{\circ}$ de Bachillerato, aprobado por el Ministerio de Educación en 2007, establece que el alumno y la alumna deberán "valorar (...) los factores que contribuyeron a desencadenar un enfrentamiento fratricida".

Ya en $5^{\circ}$ de primaria, la editorial Anaya, explica que "la guerra se produjo porque no se respetaron las normas democráticas". Pero no se aclara quién "no respetó" las normas democráticas. El término "se", impersonal, parece difuminar las responsabilidades. Puede inducir a error la posible interpretación que esta expresión conlleva, haciendo referencia, no al golpe de estado militar contra la democracia existente, sino a la situación de la II República donde, según cómo se lea la frase, no se respetaban las normas democráticas. Los tres párrafos que dedica este manual al período que comprende la guerra civil y la dictadura termina con la siguiente frase: "al terminar la guerra civil, se implantó una dictadura, es decir, un gobierno no democrático. Esa dictadura estuvo dirigida por el general Francisco Franco y duró casi cuarenta años. Durante ese tiempo no hubo libertad". Reducir una dictadura a "gobierno no democrático" y despachar ese tiempo con la característica de que "no hubo libertad" es, cuando menos, especialmente poco riguroso y bastante frívolo.

De nuevo, la editorial Edelvives asegura que uno y otro lado provocaron las "mismas víctimas", cuando los datos recogidos por la historiografía actual demuestran que, a medida que se conocen nuevas investigaciones, la represión franquista sigue subiendo y distanciándose cada vez más de la republicana, siempre inferior a las cifras manejadas por la dictadura y sus hagiógrafos. La editorial Santilla en sus libros de $2^{\circ}$ de Bachillerato afirma: "Lo que no resulta de momento precisable es el número de represaliados de cada bando, pero es probable que las cifras resulten bastante semejantes, sobre todo teniendo en cuenta las ejecuciones llevadas a cabo por el general Franco al final de la guerra civil". En este manual la represión de los golpistas se limita al período de la guerra: "Puede decirse que la represión se produjo sobre todo en los primeros momentos del estallido". 
En el manual de Historia de España de $2^{\circ}$ de Bachillerato, de la editorial Akal, las muertes de la represión quedan reducidas a un "cuadro detalle" en el capítulo de balance, dentro de las 50 páginas que dedica a la guerra civil y al franquismo; y no explica quién, cómo, ni por qué se fusilaba; a los 'paseos' les dedica apenas una frase. Encontramos que los 44 años que duraron la II República, la guerra civil y la dictadura franquista ocupan sólo el 10\% de los contenidos del siglo XX en los libros de texto más utilizados por nuestro alumnado. Igualmente señalar que, dentro de ese 10\%, el mayor espacio lo ocupa la descripción de la guerra civil, seguido por la época de la II República, pero que la represión de la dictadura y la lucha antifranquista prácticamente están ocultas en los libros de texto.

Hemos de ser conscientes que la edición de cada libro de texto está muy pensada y que su diseño y composición responden a un trabajo riguroso y pormenorizado, que no deja nada prácticamente al azar. Por lo que las supuestas "lagunas" u "olvidos" no son inocentes. Cuando se quiere los textos, las imágenes, incluso las leyendas de las mismas se cambian y modifican conforme al interés determinado que persiguen. Por ejemplo, el libro de Santillana de Historia de $4^{\circ}$ de la ESO, presenta una versión para el país Vasco donde, en el tema dedicado a "España: del franquismo a la democracia", la imagen que inicia el tema es diferente a la versión del resto del Estado: desaparece la figura del rey siendo sustituida por otra fotografía. Lo cual significa que el currículum que se presenta en los mismos obedece a una determinada visión sobre los acontecimientos ante la que hemos de ser críticos y exigentes.

\section{Construyendo alternativas: Materiales didácticos para evitar la "amnesia" histórica}

Buena parte de las investigaciones se quedan en la descripción de la realidad, incluso algunas avanzan en el cuestionamiento de la misma, pero son pocas las que dan un paso más y generan propuestas y alternativas que palíen o traten de remediar aquellos aspectos de la realidad que han hallado deficitarios o irregulares. En este sentido, decidimos proponer una alternativa que llenara este vacío en la formación de nuestras futuras generaciones. 
De ahí que nos embarcáramos en un segundo proyecto más allá de la investigación teórica: realizar una unidad didáctica con el fin de recuperar esa parte de nuestra historia que ha quedado relativamente olvidada o silenciada en el currículum escolar habitual ${ }^{14}$. Aunque inicialmente el proyecto fue hacer una unidad didáctica, al ir profundizando y desarrollando los contenidos, los materiales, las actividades, el trabajo en definitiva, decidimos hacer tres unidades didácticas en formato de libro de texto. La primera centrada en la Causa Republicana, la segunda en la represión franquista y la última en la resistencia antifranquista, incluyendo un apartado final dedicado al fenómeno actual de la recuperación de la "memoria".

El hecho de diseñarlas y publicarlas con el formato habitual que utilizan cualquiera de los libros de texto de bachillerato obedecía al propósito de presentar este material curricular complementario, tanto al profesorado como al alumnado, con una "imagen" similar a la que están acostumbrados con los libros de texto habituales. No sólo con la intención de dignificar los hechos históricos, las ideas y las vidas de tantos hombres y mujeres que lucharon por la causa de la libertad y la justicia, sino también porque la similitud con el libro de texto le confiere "fiabilidad" y cercanía al currículum oficial. Pues nuestra pretensión última es que estas unidades didácticas, o parte de ellas, no permanezcan como materiales complementarios que pueda utilizar aquel profesorado o alumnado que esté interesado o tenga cierta afinidad con los planteamientos en ellas desarrollados, sino que las editoriales incorporen progresivamente sus contenidos a los libros de texto de Historia, pues dichos contenidos son parte del currículum oficial.

Mientras tanto, con estas tres unidades didácticas tratamos de facilitar una herramienta de trabajo, amena y atractiva, que ayude al profesorado, especialmente en segundo de bachillerato, en su labor docente. Ofreciéndoles un material que puedan insertar en el currículum ordinario de la materia, con actividades adecuadas a las edades de

${ }^{14}$ DÍEZ GUTIÉRREZ, E.J. (Dir.). (2009): Unidades Didácticas para la recuperación de la memoria histórica. León, Foro por la Memoria de León. Publicación realizada en colaboración con Javier Rodríguez González, profesor de Historia Contemporánea de la Universidad de León. 
su alumnado y lo suficientemente diversas como para que se puedan adecuar a las características y capacidades de todos y cada uno de los componentes del grupo.

Cada unidad didáctica está organizada con una estructura similar. Todas ellas se inician con un mapa conceptual gráfico, donde se identifican los contenidos esenciales que se desarrollan en el tema y se representan gráficamente sus relaciones, de forma jerárquica en función de su importancia y globalidad, a través de líneas y términos de enlace que los conectan de forma significativa entre sí. De esta forma se puede ver, de forma gráfica y global, la estructura global de la unidad de un "solo vistazo".

Los contenidos históricos se presentan mediante textos informativos, sencillos y directos, así como completos y rigurosos, que comprenden los principales datos y conceptos sobre la temática propuesta. El color del texto del título y de la banda vertical, que divide las páginas, es diferente en función de la unidad didáctica que se está tratando, con el fin de que el alumnado pueda ubicar los contenidos de forma permanente y rápida. Los textos explicativos se acompañan con ilustraciones, imágenes y fotografías relacionadas con la temática, que ayudan al alumnado a situarse en la época histórica, pues reflejan gráficamente cómo era la realidad en ese momento. Los pies de foto identifican y explican las ilustraciones y fotografías, aclarando y añadiendo información significativa. También se incluyen frases "sorprendentes", curiosidades, para ampliar la información y hacer más útil y agradable el trabajo con los contenidos.

Por supuesto, todas las unidades incluyen esquemas, mapas, cronologías y gráficos que sirven de apoyo, resumen y recogida de datos para ampliar los contenidos. Se han recogido también fragmentos de textos históricos que se resaltan, pues aportan una interesante visión sobre los acontecimientos de la época desde el punto de vista de sus propios autores o autoras. Además, se insertan algunas biografías, discursos o relatos sobre destacados personajes que fueron importantes en ese momento histórico.

Cada unidad didáctica viene acompañada por algunas páginas especiales destinadas a bibliografía sobre el tema, testimonios directos 
de la memoria personal de los protagonistas y actividades sobre la materia desarrollada. Las páginas de bibliografía presentan una parte destinada a bibliografía básica de consulta, es decir, un listado de libros y artículos de autores y autoras de referencia para poder consultar, ampliar y seguir trabajando sobre la temática de la unidad didáctica. En ella están todos los autores y autoras citados a lo largo de la misma. Un segundo apartado dedicado a obras literarias donde se incluyen novelas y relatos literarios relacionados con la unidad didáctica, haciendo un breve resumen crítico sobre las mismas. El tercer bloque bibliográfico se dedica a las películas: un breve listado de películas sobre la materia, con un pequeño resumen, que se pueden utilizar didácticamente en el aula para analizar y profundizar en la temática de la unidad didáctica. Por último, dado que internet ofrece múltiples materiales y recursos de consulta y ampliación de los contenidos, se presenta un bloque final con algunas de las páginas web más directamente relacionadas con la temática, explicadas y comentadas.

Las páginas de testimonios recuperan testimonios, documentos y relatos de personas que vivieron directamente, o a través de las crónicas de sus familiares, los acontecimientos que se describen en estas páginas, dando una visión más personal y emotiva de los acontecimientos históricos que la narrada desde la distancia por los historiadores e historiadoras especialistas en el tema. Las páginas de actividades ofrecen un extenso elenco de propuestas de tareas y actividades para realizar con el alumnado, con el fin tanto de profundizar en la comprensión global del tema, como en el análisis de los textos y documentos gráficos ofrecidos a lo largo de la Unidad didáctica. Las actividades son abundantes y su grado de complejidad variable se ha graduado progresivamente. A lo largo de las tres unidades didácticas se ofrecen más de cien actividades para trabajar en el aula, de las cuales el profesorado podrá aprovechar aquellas que le parezcan más significativas y relevantes para el trabajo didáctico que está desarrollando. Pero también le ofrecerá la oportunidad de poder brindar a su alumnado una batería diversificada y amplia de actividades para poder ajustarla a las necesidades y posibilidades de cada uno de ellos.

Por eso las actividades de cada unidad didáctica se han dividido en tres bloques: actividades de comprensión global del tema, actividades de análisis de textos y actividades de refuerzo y ampliación. Las primeras, de 
comprensión del tema, proponen actividades que permiten autoevaluar y evaluar el grado de entendimiento y comprensión que sobre el tema ha conseguido adquirir el alumnado. De esta forma pueden servir de evaluación procesual, facilitando una visión de las dificultades y progresos que tiene el alumnado. Las segundas, de análisis de textos, permiten que el alumnado tenga un contacto directo con las fuentes documentales directas, proponiéndoles diferentes tareas de trabajo con ellas, de tal forma que puedan manejar, analizar y comentar críticamente diversas fuentes históricas primarias. Finalmente, las actividades de refuerzo y ampliación están dirigidas para aquel alumnado que pueda y quiera seguir trabajando y profundizando en la materia de la unidad didáctica ofreciéndole posibilidades de ampliar y desarrollar otras tareas de investigación, elaboración de materiales textuales o gráficos para comunicar y difundir sus hallazgos o, incluso, de implicación activa en movimientos de recuparación de la memoria histórica.

Los objetivos que se pretenden conseguir con toda esta propuesta van dirigidos no sólo a que el alumnado adquiera el "saber" histórico, comprenda el conjunto de acontecimientos, conceptos y procesos que conforman este período histórico; sino que buscan desarrollar también, a través de cada unidad didáctica, una serie de valores y actitudes que implica el saber y que permiten emitir juicios de valor fundamentados. Algunos de los más significativos hacen referencia al "interés por conocer los acontecimientos de la Segunda República y de la posterior lucha antifranquista, para comprender las raíces de la actual democracia española", a la "capacidad de ponerse en el lugar de los actores y actrices históricos que han sido ignorados u ocultados", a la "adopción de un método de trabajo ordenado y riguroso en el estudio histórico" o a la "curiosidad por conocer tanto los procesos fundamentales como los hechos acontecidos", así como la "apertura de mente y tolerancia, sin indiferencia, para valorar críticamente las diversas concepciones e interpretaciones de la historia". Como podemos ver se tratan de actitudes y valores que el propio currículum oficial establece para esta materia y para este período de estudio.

Las competencias que buscan alcanzar estas unidades didácticas tienen que ver con "aprender a identificar y situar en el tiempo y en el espacio los procesos, estructuras y acontecimientos más relevantes de la historia de la época de la Segunda República Española, así 
como la posterior represión y lucha antifranquista contra un régimen dictatorial, valorando las repercusiones que tuvo en la configuración de la España actual y de la sociedad contemporánea". Tienen que ver con "fomentar una visión completa de esta época de la historia de España, que respete y valore la vida y la lucha de quienes han sido relegados históricamente en las crónicas contemporáneas generando actitudes de solidaridad y respeto por los valores democráticos instaurados y defendidos por los republicanos y republicanas", así como "ejercer la ciudadanía democrática, desde una perspectiva global, y adquirir una conciencia cívica responsable, inspirada por los valores de la Constitución democrática así como por los derechos humanos, que fomente la corresponsabilidad en la construcción de una sociedad justa y equitativa".

Por lo tanto, como podemos ver, la pretensión de estas unidades no es simplemente iniciar al alumnado en los procesos de investigación didáctica de una realidad ocultada y facilitarles procedimientos y materiales para que se adentren en el descubrimiento de parte de la historia que ha conformado la sociedad que ahora tienen, sino también conectar los principios por los que lucharon los defensores de la República con los principios democráticos y sociales que hoy día se han consagrado en la Declaración Universal de los Derechos Humanos y "desde el conocimiento de la realidad y los principios democráticos que defendieron sus antecesores, alumbrar un espíritu que les permita participar de forma solidaria en el desarrollo y mejora de su entorno social, involucrándose en la construcción de una sociedad más justa y mejor".

Por eso, se diseñaron estas unidades didácticas con la intención, como dice Rosa Regás , de cumplir "un deber histórico y ciudadano: que la Historia de España a través de sus historiadores y de la enseñanza, devuelva la Segunda República al lugar que le corresponde, (...) lo cual deberían aprovechar las escuelas para reparar el silencio que han mantenido sobre la Segunda República no sólo durante la dictadura sino también en los años de democracia, un silencio que selló la transición pero que ya va siendo hora de denunciar, de modo que los estudiantes conozcan de una vez esta parte tan hermosa de la historia de nuestro país

${ }^{15}$ REGÁS, R. (2006): Aquella Segunda República. Los fascistas reescribieron la bistoria para poder justificar su insurgencia como inevitable. El Periódico, 08 de enero. 
y entiendan que con la fe en las ideas democráticas es posible avanzar hacia un mundo un poco mejor".

En cuanto a los contenidos se han plasmado en tres bloques fundamentales: la Segunda República, la represión franquista y la lucha antifranquista. Destacamos algunos aspectos, que nos parecen suficientemente significativos. Dado que la primera unidad didáctica es la más conocida y explicada en los libros de texto utilizados habitualmente en los centros educativos, en ella hemos querido destacar especialmente aspectos que a veces no se resaltan con la suficiente amplitud o profundidad: en concreto, los principios que inspiraban la II República y las reformas que se llevaron a cabo o se iniciaron en esta etapa histórica. Haciendo hincapié en las causas y los motivos que dieron origen a esta "revolución democrática" y el despertar que supuso en la España de entonces. En esta unidad apenas hemos dedicado cinco párrafos a la guerra civil, puesto que los sucesos que la marcaron están descritos pormenorizada y extensamente en la inmensa mayoría de los libros de texto.

Los contenidos de la segunda unidad didáctica son mucho más desconocidos para buena parte de los estudiantes que acaban el bachillerato. Especialmente el carácter sistemático y organizado de la represión de la dictadura franquista, que se ejerció incluso con carácter retroactivo sobre todos aquellos y aquellas que habían defendido la causa republicana, pertenecido a sindicatos, o simplemente habían sido simpatizantes o cercanos a la legalidad democrática vigente en la II República.

Se describe cómo la dictadura franquista se construyó ejerciendo la represión en sus más variadas formas -política, económica, social, cultural, administrativa y de género-. Añadiéndose la depuración que alcanzó a los sectores más variados de la sociedad, siendo especialmente castigados los funcionarios y funcionarias de la administración y los docentes. Pero hemos querido destacar significativamente la regulación legal de la represión a través de las tres principales leyes que constituyeron el pilar fundamental de la represión que se inició inmediatamente al golpe de Estado con el Decreto del 24 de julio de 1936, seguido del Bando del 28 de julio del mismo año. No olvidamos 
aquí tampoco hacer un análisis comparativo de las cifras de la represión basado en las más recientes fuentes historiográficas, así como dedicar un extenso epígrafe a los refugiados y exiliados que tuvieron que continuar su vida fuera de su tierra y su país.

Quizá sean los contenidos de la tercera unidad didáctica los que rescatan una parte de la historia de nuestro país no simplemente olvidada, sino realmente silenciada o, al menos, claramente ocultada en los libros de texto escolares. Es la dedicada a la resistencia antifranquista. Ya al inicio del golpe de estado, el 28 de julio, Franco declaraba en Tánger al periodista norteamericano Jay Allen, del Chicago Daily Tribune, que estaba dispuesto a acabar con la mitad de los españoles si ello era necesario para pacificar el país. Declaraciones de este tipo fueron efectuadas con mucha frecuencia por buena parte de los mandos militares franquistas a lo largo de la contienda civil. Así, el capitán Gonzalo de Aguilera, conde de Alba de Yeltes, le dijo al periodista norteamericano John T. Whitaker, del The News York Herald Tribune, que había que "matar, matar y matar" a todos los rojos, para extirpar el virus bolchevique y librar a España de "ratas y piojos". Este clima de terror llevó a decenas de militares republicanos, a militantes de sindicatos y partidos políticos y a simpatizantes y defensores de la República a ocultarse en las zonas montañosas de España, a la espera de que llegasen mejores tiempos y disminuyese la intensidad de la represión, para entonces entregarse a las nuevas autoridades. Estos "huidos al monte" que escapaban de la represión serían el embrión de la posterior resistencia guerrillera que, con el paso de los años y en clara sintonía con la evolución de la política internacional, tomaría la forma de lucha armada contra el régimen franquista. No obstante, desde los primeros momentos hubo intentos de organización por parte de algunos miembros de los eliminados partidos políticos. Los primeros fueron los comunistas y anarquistas, incluso desde los propios campos de concentración, como el de Albatera en Valencia, pero sus intentos fueron sofocados por el régimen.

Partiendo de estos planteamientos, esta unidad didáctica se centra en la oposición interior, en los huidos y en los topos, así como en la solidaridad de la población con este germen de la resistencia, destacando especialmente el papel de los enlaces. De huidos fueron pasando a organizarse como guerrilla, alguna de cuyas federaciones llegó a tener incluso escuela de formación. Un capítulo especial se dedica al intento de 
invasión por el Valle de Arán y se cierra con los epígonos de la guerrilla urbana hasta el final de la misma a mediados de los años 60.

Por último, dentro de esta tercera unidad didáctica, se dedica un apartado al movimiento social de la denominada "generación de los nietos y las nietas" que se han dedicado a la recuperación de la memoria histórica, mediante iniciativas de todo tipo: desde homenajes, hasta publicaciones de libros, videos y documentales, pasando por la búsqueda, localización y exhumación de las personas fusiladas. Este movimiento social propugna que se revise la historia tal y como ha venido siendo contada por los vencedores, en lo que se refiere a la política, la historia y los símbolos, para recuperar el conocimiento de las acciones de resistencia de los demócratas españoles en su lucha contra la dictadura de Franco y el rigor histórico en los acontecimientos de la Guerra Civil y la represión. De ahí la inclusión de este apartado, facilitando que el alumnado vea un aspecto de las conexiones de la historia con el momento presente.

Por eso, se cierra esta última unidad didáctica con el proceso para investigar los crímenes cometidos por el franquismo que inició el juez Baltasar Garzón el 16 de octubre de 2008, tratando de establecer la responsabilidad penal del general Francisco Franco y otros 44 miembros de sus Gobiernos y jefes de Falange, a los que acusaba de "delitos contra Altos Organismos de la Nación y la forma de Gobierno", así como de "detención ilegal con desaparición forzada de personas", en un marco de "crímenes contra la humanidad". Este hecho que le ha valido a dicho juez el haber sido sentado en el banquillo de los acusados por organizaciones profranquistas, sirve como colofón para mostrar al alumnado la actualidad y permanencia de la memoria histórica en nuestro país.

La metodología didáctica que se propone para trabajar los contenidos de las unidades se basa en una concepción del proceso de enseñanzaaprendizaje que busca partir del nivel de desarrollo del alumnado y de sus aprendizajes previos, para asegurar la construcción de aprendizajes significativos a través, tanto de la movilización de sus conocimientos previos, como de la memorización comprensiva, posibilitando que progresivamente los alumnos y las alumnas realicen aprendizajes significativos de forma cada vez más autónoma. También se pretende 
favorecer situaciones en las que los alumnos y alumnas actualicen sus conocimientos y los pongan en relación con el contexto en el que viven, proporcionándoles experiencias de aprendizaje que resulten motivadoras.

De ahí que se proponga una metodología basada en actividades motivantes que faciliten la atención a la diversidad. En este sentido se proponen actividades abiertas, para que cada alumno y cada alumna las realice según sus posibilidades, ofreciendo esas actividades con una gradación de progresiva dificultad en cada unidad didáctica. También se propone organizar los aprendizajes mediante proyectos que - a la vez que les motiven - les ayuden a relacionar y aplicar conocimientos, aprovechando situaciones de heterogeneidad, como los grupos cooperativos, que favorezcan la participación e implicación del alumnado en el proceso de enseñanza-aprendizaje.

Para lograrlo, se debe iniciar cada unidad didáctica con una breve evaluación inicial que permita calibrar los conocimientos previos del grupo en ese tema concreto, para facilitar la significatividad de los nuevos contenidos, así como organizar en el aula actividades lo más diversas posible que proporcionen diferentes tipos y grados de ayuda. Cuando se detecte alguna laguna en los conocimientos de determinados estudiantes, puede utilizarse alguna de las actividades de refuerzo propuestas, con el fin de subsanarla.

En cada tema, los contenidos se presentan de forma categorizada y organizada. La división en epígrafes y subepígrafes está destinada a facilitar la selección de los mismos. Las páginas iniciales de cada unidad se han diseñado para presentar el tema de una forma integradora y motivadora, pero también para generar un debate sobre los contenidos del tema. El profesor o profesora puede utilizarla para realizar preguntas destinadas a explorar los conocimientos previos y ajustar posteriormente el nivel de contenidos que impartirá.

Por tanto, la planificación de cada unidad didáctica tiene en cuenta que no todos los alumnos y alumnas alcanzarán de la misma manera los objetivos, seguirán el mismo proceso de aprendizaje y aprenderán exactamente lo mismo, pero asegura un nivel mínimo a todo el alumnado. Este es el motivo por el que se tratan los conceptos más 
difíciles de forma gradual y con actividades diferentes. Esta forma de actuar asegura la comprensión, proporciona confianza al alumnado y favorece la funcionalidad del aprendizaje.

En resumen, la intención de estas Unidades Didácticas ha sido, por tanto, recuperar una parte de nuestra historia que ha quedado olvidada en formato de libro de texto, con más de cien actividades para desarrollar en las clases de historia, especialmente en $2^{\circ}$ de Bachillerato, aunque muchas de estas actividades ya se están utilizando actualmente por profesorado de $4^{\circ}$ de la ESO en sus clases. No obstante, son contenidos y actividades que se pueden trabajar en cualquier momento y ámbito, si se está interesado en ello, adaptándolas a las circunstancias y características del público al que vaya dirigida la propuesta formativa. Pero quisiéramos propiciar que estas Unidades Didácticas sean el germen de otras Unidades Didácticas, en diferentes partes del Estado, que progresivamente vayan recuperando aspectos y retazos de esta realidad histórica localizados en las diferentes zonas y realidades que componen la geografía nacional.

\section{Lecciones contra el olvido: evitar el olvido y construir una ciudadanía democrática}

Habitualmente, los trabajos sobre la recuperación de la memoria histórica de las víctimas republicanas y de la represión de la postguerra civil se quedan reducidas a personas expertas, especialistas o asociaciones interesadas en estos temas, pero raramente trasciende al acerbo colectivo de la memoria social, especialmente de nuestras jóvenes generaciones, que, como hemos visto, desconocen o conocen esta parte de la historia desde una visión supuestamente "neutral y aséptica", pero que encubre graves silencios y ocultamientos deliberados de una parte de la historia que nos pertenece a todos y todas, a la sociedad en su conjunto. Por eso los y las adolescentes de nuestro tiempo, se ha dicho con razón, poseen una "memoria fragmentada".

La guerra civil marcó tanto la memoria de sus protagonistas directos e indirectos como la de sus descendientes y la de las generaciones futuras. Porque la guerra civil y la represión posterior constituyen "un pasado que no acaba de pasar", cuyo lastre y heridas siguen muy 
presenten no sólo en quienes lo sufrieron y en sus familias, sino en la visión colectiva heredada del franquismo. Como dice Ruiz-Vargas, no solamente debido a la crueldad de los tres años de guerra y los cuarenta años siguientes de sistemática represión por la dictadura, mediante el terror institucionalizado y la violencia bajo diferentes formas (asesinatos extrajudiciales, represión «legal», prisión política, internamiento en cárceles y campos de concentración, trabajo forzoso, exilio, depuraciones, fusilamientos, tortura, hambre, control social, degradación y humillación de los vencidos,...), sino a la implicación activa de una parte de la sociedad civil (la que se sentía vencedora) en el plan de represión, intimidación y exclusión social de la dictadura franquista, lo cual condenó a los vencidos al peor de los castigos: ser cautivos en su propia tierra, en su propia casa, desposeídos de sus derechos y estigmatizados de por vida. Esas víctimas derrotadas, se vieron obligadas a tragar sus lágrimas y su dolor, a ocultar o renegar de sus ideas, a sentir vergüenza de su condición ideológica, a autoimponerse el más férreo de los silencios; en definitiva, tuvieron que ahogar su propia memoria y con ella toda posibilidad de elaboración, duelo y superación de los horrores de la guerra. En cambio, los vencedores abusaron de la evocación del triunfo, día tras día, durante cuarenta años.

Como afirma este experto Ruiz-Vargas, todas las víctimas de la violencia represiva de una dictadura sufren una doble ofensa: la agresión de sus verdugos y la tortura psicológica de intentar borrarlos de la memoria. Son condenadas a convivir íntimamente con sus represores, unido al hecho de privarlas deliberadamente de toda oportunidad de hablar y de contar su dolor; condenándolas cruelmente a un silencio torturante y obligándolas a reprimir sus recuerdos, ante la esperanza vana de sus opresores de que el tiempo acabará borrando lo que otros no deberían conocer. No será el tiempo el que devuelva la reconciliación mientras existan memorias amordazadas. El tiempo como tal no resuelve ni cura nada. Porque no se trata de olvidar, sino de que la memoria individual y compartida que impuso el franquismo metabolice la memoria dolorida de las víctimas reconociendo su verdad. Porque la reivindicada "memoria histórica" es la recuperación de la verdad desde la memoria herida de las víctimas, concluye.

En la última década el interés por reflexionar sobre nuestro pasado inmediato que se ha extendido en nuestra sociedad, en particular por 
tratar de recuperar la voz de los sectores defensores de la II República y de las víctimas de la represión franquista se debe, ciertamente, a que todavía hoy la memoria pública y colectiva difiere sustancialmente de las conclusiones a las que nos conducen los estudios históricos y la memoria individual silenciada. Desde sus inicios, la dictadura franquista desarrolló una política de la memoria que procuró por todos los medios demonizar, y posteriormente hacer desaparecer, la memoria de la Segunda República y así poder consolidar una nueva memoria colectiva afín a sus propósitos. La maquinaria del silencio y la negación, cuyo fin último es el olvido, buscaba un completo dominio sobre la memoria, la cancelación del recuerdo y la imposición de los paradigmas oficiales.

La transición a la democracia traía consigo cuarenta años de asentamiento de ese "inconsciente colectivo", de recreación constante de los postulados franquistas sobre el origen de la guerra civil, la barbarie "roja" y la necesidad del "orden" franquista. Durante este período de transición, la supuesta "necesidad de consolidar el régimen democrático" y el miedo y control generado por la continua alusión al "ruido de sables", condicionó la posibilidad de desarrollar una política de la memoria que enlazase con la tradición democrática republicana. Esto ha significado una escasez de la democracia española, como consecuencia de la inexistencia durante el proceso democratizador de algún tipo de justicia retroactiva para enjuiciar los crímenes cometidos durante la guerra y la dictadura por parte de los vencedores, extendiendo también hacia el pasado la omisión de lo social ${ }^{16}$.

Tampoco cuando la democracia ya estuvo consolidada, los gobiernos sucesivos tuvieron interés en desarrollar una política de la memoria basada, no sólo en la exaltación de los valores democráticos sino, también, en la reivindicación de aquéllos que habían luchado contra el franquismo y que, con su esfuerzo, fueron una pieza esencial en la instauración de la actual democracia. Es decir, durante mucho tiempo, la falsa memoria recreada por el franquismo no se vio contrarrestada institucionalmente con una nueva política de la memoria sustentada en referentes democráticos pasados y presentes. De esta forma los valores de los perdedores de la guerra fueron excluidos del imaginario colectivo

\footnotetext{
${ }^{16}$ NAVARRO, V. (2002): Bienestar insuficiente, democracia incompleta. Sobre lo que no se babla en nuestro pais. Barcelona, Anagrama.
} 
y de la representación social del pasado, quedando su memoria proscrita al ámbito individual o familiar y sobreviviendo y consolidándose los valores políticos dictatoriales, como antítesis de los defendidos por sus vencidos, en la que resultaría ser una suerte de "democracia relativista". Lo cierto es que el "memoricidio", como fue descrito por Primo Levi, que intentó llevar a cabo el franquismo ha sobrevivido décadas al final de la propia dictadura, mediante una suerte de cultura del miedo ${ }^{17} \mathrm{y}$ del silencio , que aún se saca a la luz nada más que se agitan un poco las demandas de justicia o de reparación histórica de las víctimas (el juicio al juez Garzón, instigado por un grupo fascista residual, por investigar crímenes contra la humanidad cometidos por las fuerzas franquistas, es un claro ejemplo de ello).

Mientras que otras democracias, como la italiana o la francesa, se fundaron sobre el paradigma del antifascismo, la española lo hizo sobre el de la "superación" del pasado y parece que quisiera mantenerse así por algunos sectores aún ligados al tardofranquismo. Si en esos países, la construcción del pasado y de las identidades colectivas ha pasado por el mantenimiento de símbolos estéticos de la lucha antifascista y de la crueldad de los regímenes anteriores, en España, sin embargo, el paradigma del antifascismo, no fue aglutinador político ni fuente de legitimidad alguna. La del naciente Estado democrático partió de un mito fundacional, la misma transición "pacíficamente" controlada, y "se desarrolló mediante una legitimidad de orden, el funcionamiento de la propia democracia en la que se hizo renuncia explícita al referente simbólico, al «lugar de la memoria» de la Segunda República como experiencia de pluralismo democrático, a la experiencia de los vencidos como guardianes de la legitimidad democrática pretérita, en aras de la gobernabilidad del país" ". Y eso, sin lugar a duda, influyó poderosamente en la construcción de una no-política de la memoria ${ }^{20}$.

\footnotetext{
${ }_{18}^{17}$ Agitando banderas del "guerra civilismo" para generar alarma social.

${ }^{18}$ RODRIGO, J. (2006): La Guerra Civil: "Memoria”, “Olvido”, "Recuperación” e

"Instrumentación", en Hispania Nova. Revista de Historia Contemporánea. 6. [Consultado

el 1 de abril de 2010 en http:/ / hispanianova.rediris.es/6/dossier/6d025.pdf]

RODRIGO, J. (2006): La Guerra Civil: "Memoria", “Olvido", "Recuperación” e

"Instrumentación", en Hispania Nova. Revista de Historia Contemporánea. 6. [Consultado

el 1 de abril de 2010 en http://hispanianova.rediris.es/6/dossier/6d025.pdf], p. 11.

SEVILLANO, F. (2003): "La construcción de la memoria y el olvido en la España democrática", en Ayer, 52, pp. 297-319.
} 
No mirar al pasado, olvidar la guerra y sus víctimas, se suponía era la "exigencia" para la "reconciliación", la primera piedra fundacional de una democratización consensuada y no violenta. Pero eso supuso renunciar al "garante" de su memoria como factor de legitimación, al "pacto del silencio", a la confusión de "amnistía con amnesia" . La Ley de Amnistía de 1977 presentada como un pacto de reconciliación entre los bandos enfrentados en la guerra civil aseguró la impunidad para los torturadores, asesinos y represores del régimen de Franco, que vieron compensado su desalojo del poder por una suerte de "amnesia judicial colectiva", consagrando un "pacto de olvido" que se quiso convertir en una ley de "punto final".

No obstante, la situación parece haber cambiado un tanto. La sociedad, especialmente entre la generación de "los nietos y las nietas de la guerra", lucha hoy por sacudirse la interiorización de esa "amnesia colectiva". Vuelve su mirada hacia esa historia oscura de represión y barbarie, reclamando conocer la magnitud de la represión y exigiendo que se reconozca moralmente a las víctimas. Las instituciones lenta y muy moderadamente están recogiendo esa demanda social; la aprobación de la Ley por la que se reconocen y amplian derechos y se establecen medidas a favor de quienes padecieron persecución o violencia durante la Guerra Civil y la Dictadura, va en este sentido ${ }^{23}$. Pero, aunque se han realizado numerosas investigaciones y publicaciones especializadas sobre este período y sobre estos acontecimientos que han vertido mucha luz sobre los mismos, lo cierto es que "no ha terminado de formar parte, precisamente debido a esa carencia, de una percepción colectiva sobre el pasado" ". Porque, como recuerda este autor, esa denominada "falsa memoria" del franquismo parece seguir presente en muchos aspectos

${ }^{21}$ VILARÓS, T. M. (1998): El mono del desencanto. Una crítica cultural de la transición española (1973-1993). Madrid, Siglo XXI, p. 67.

AGUILAR FERNÁNDEZ, P. (2001): Justicia, politica y memoria. Los legados del franquismo $e_{23}$ la transición española. Madrid: Instituto Juan March de Estudios e Investigaciones.

Aunque ha recibido profundas críticas por asumir una cierta "desmemoria" interesada, al renunciar a rendir cuentas del pasado, estableciendo disposiciones específicas para salvaguardar la identidad de los presuntos autores de los abusos a las víctimas; negando la anulación de sentencias de los consejos de guerra, tribunales de responsabilidades políticas y juicios sumarísimos; o eludiendo la responsabilidad del propio Estado en la localización, exhumación e identificación de las víctimas de la Guerra Civil y la represión franquista, dejándolo en manos de asociaciones y colectivos mediante subvenciones o trabajo voluntario. 
de la vida cotidiana, desde las series televisivas hasta los libros de texto escolares, pasando por innumerables subproductos bibliográficos en los que no se percibe, ni por asomo, atisbo alguno de investigación. "Precisamente por eso, algunos de los títulos recientes que encarnan el revisionismo de la para-historiografía de derechas se dedican «a los jóvenes» y los convidan a superar las supuestamente anquilosadas en lo «políticamente correcto» visiones de la guerra y el franquismo provenientes de la academia y la historiografía profesional" ${ }^{25}$.

Este relativo impulso a la recuperación de la memoria democrática por parte de las instituciones no implica de ninguna manera participar en la confrontación de memorias, sino asegurar la incorporación del conocimiento riguroso del pasado a la memoria pública, lo que en el caso español supone transmitir a las nuevas generaciones el significado de la Segunda República, el franquismo y el antifranquismo a la luz de los valores democráticos. Una política pública de la memoria debe tener como objetivo proclamar solemnemente la vigencia de los valores democráticos por lo que vivieron y, tantas veces, murieron los que defendieron la República, como fundamento de la organización y convivencia social actual.

Como plantea Vinyes ${ }^{26}$ los ciudadanos y las ciudadanas somos depositarios y herederos naturales de la historia, del recuerdo y la memoria. El olvido es el impedimento de acceso al conocimiento, es único y es sólido y tiene por objetivo que sólo se acepte una versión del pasado, para destruir así la memoria diversa; por eso las dictaduras tienen en el olvido el recurso imperativo y necesario que consolida su cultura, y por tanto su poder y su consenso. La democracia tiene que fomentar el acceso de la ciudadanía al conocimiento histórico porque es la única garantía de respeto a la pluralidad de memorias, permite la adquisición de criterios propios y hace a los ciudadanos y a las ciudadanas civilmente más sabios, y por lo tanto más libres. Las políticas institucionales de la memoria dicen mucho de los valores éticos y cívicos subyacentes en un sistema político. La memoria pública es crucial y necesaria. Por

\footnotetext{
${ }^{24}$ RODRIGO, J. (2006): La Guerra Civil: "Memoria”, “Olvido", "Recuperación” e "Instrumentación". Hispania Nova Revista de Historia Contemporánea N. 6, p. 56.

${ }^{25}$ Un ejemplo de ello es el artículo de Francisco Rodríguez Sánchez (2008) titulado La República y La Guerra Civil en los libros de texto de Bachillerato, en la revista Historia Abierta, N. 40, pp. 12-33.

${ }^{26}$ VINYES, R. (Coord.). (2004): Un futuro para el pasado. Barcelona, CEFID.
} 
esa razón el conocimiento histórico ha sido considerado por muchos estados democráticos como un derecho civil que los gobiernos han de garantizar y promover, declara este experto.

Por eso, este proyecto de elaboración de "unidades didácticas para la recuperación de la memoria histórica" ha tratado de reconstruir un currículum contra hegemónico que garantice la justicia curricular. (Re)construir un pasado dentro de un marco de referencia colectivo y desde el presente, de tal forma que la experiencia y las memorias de las personas olvidadas y desfavorecidas formen parte también del currículum oficial. Un currículum, construido a partir de la posición de los grupos subordinados, que invierta la hegemonía. No para "dar la vuelta a la tortilla", sino para proporcionar experiencias e informaciones desconocidas y olvidadas, para hacer un currículum más comprensivo, más representativo. Esto supone replantear la historia desde la perspectiva de los perdedores, los grupos oprimidos, represaliados, olvidados. Y combinar las memorias de las víctimas con la historiografía más actual . La utilidad principal de la "memoria colectiva" es el aprendizaje colectivo, la utilización del pasado (sobre todo, del traumático) como enseñanza para el presente mediante la articulación de sus usos públicos, dentro de los cuales las asignaturas de Historia en la enseñanza obligatoria son cruciales.

\section{CONCLUSIÓN}

En consecuencia, la realización de acciones y propuestas destinadas a garantizar el derecho de la ciudadanía al conocimiento histórico veraz, no ya del pasado nacional lejano, sino de la devastación humana que sufrió el mundo desde la aparición del fascismo en la década de 1920, y de los genocidios que éste perpetró por razones raciales, ideológicas y culturales, es hoy en día una realidad con prestigio en los principales países de la Unión Europea. Pero también en Estados Unidos y Canadá, en Argentina y Chile, en Australia y en Japón; y la memoria de las dictaduras se extiende a países como Ruanda o Sudáfrica con la voluntad de explicar la magnitud de los enfrentamientos civiles y los regímenes dictatoriales que los provocaron.

${ }^{27}$ TODOROV, T. (2002): Memoria del mal, tentación del bien. Indagación sobre el siglo XX. Barcelona, Península, p. 67. 
En casi todos lados, de Alemania a Inglaterra, de Italia a Francia, de Argentina a Polonia, el "recuerdo colectivo" de la "memoria traumática" asalta regularmente al presente, reclamando "deberes cívicos" de "rememoración"; invade y llena los espacios públicos y los centros de decisión política para "restituir" dignidades y "revisar" el pasado. Recuperar la memoria de las víctimas de la represión franquista como base de la ciudadanía democrática es un deber del Estado español, no sólo de las iniciativas personales de expertos o personas interesadas, ni siquiera de asociaciones o colectivos militantes. Pues afirma la calidad de la democracia y es una inversión de futuro porque no se debe de olvidar que la identidad se construye en buena medida con el material de la memoria ${ }^{28}$.

De ahí que esta iniciativa de unidades didácticas debería ser potenciada y extendida por todo el territorio nacional e incorporada en los libros de texto habituales de nuestros centros educativos, ya no como material curricular añadido o complementario, sino como contenidos propios del currículum escolar de los diferentes cursos académicos. Es responsabilidad de nuestras autoridades y a ellas les emplazamos para que asuman esta tarea urgente y necesaria.

\section{FUENTES}

REGÁS, R. (2006): Aquella Segunda República. Los fascistas reescribieron la historia para poder justificar su insurgencia como inevitable. El Periódico, 08 de enero.

SÁNCHEZ-LAFUENTE RECENA, J. (2008): ¿Qué tratamiento se da a la II República, a la Guerra Civil y al Franquismo en los libros de texto de historia de $4^{\circ}$ de ESO?, en La recuperación de la memoria histórica: una perspectiva transversal desde las ciencias sociales (195-202). ACOSTA BONO, G.; DEL RÍO SÁNCHEZ, A. y VALCUENDE DEL RÍO, J.M. (Coords.). Sevilla, Fundación Centro de Estudios Andaluces (CENTRA).

${ }^{28}$ MOLINERO, C. (2004): Memoria y Democracia. El País, 7 de noviembre de 2004. 
Análisis de los Textos Escolares de Historia. Estudio de Caso sobre Pos-Guerra Civil España

\section{REFERENCIAS}

AgUILAR FERnÁNDEZ, P. (2008): Politicas de la Memoria. Memorias de la Politica. Madrid, Alianza Editorial.

AGUILAR FERNÁNDEZ, P. (2001): Justicia, politica y memoria. Los legados del franquismo en la transición española. Madrid, Instituto Juan March de Estudios e investigaciones.

APPLE, M. W (1986): Maestros y textos. Una economía política de las relaciones de clase y sexo en educación. Barcelona, Paidós-MEC.

BALLADA, A. (2004): Desaprender la guerra. Una visión crítica de la educación para la paz. Barcelona, Icaria.

COLOM GONZÁLEZ, F. (2010): Reconciliación y memoria histórica. Claves de razón práctica.

COOK, T. D. y REICHARDT, CH. S. (1986): Métodos cualitativos y cuantitativos en investigación evaluativa. Madrid: Morata.

DÍEZ GUTIÉRREZ, E.J. (Dir.). (2009): Unidades Didácticas para la recuperación de la memoria histórica. León, Foro por la Memoria de León.

DÍEZ GUTIÉRREZ, E.J. (2007): La Globalización neoliberal y sus repercusiones en la educación. Barcelona, El Roure.

ERICE SEBARES, F. (2009): Guerras de la memoria y fantasmas del pasado. Uso y abusos de la memoria colectiva. Oviedo: Eikasia.

FAIRCLOUGH, Norman. (1992): Discourse and Social Change. Cambridge, Polity Press.

FERNÁNDEZ SIERRA, J. y SANTOS GUERRA, M. A. (1992): Evaluación cualitativa de programas de educación para la salud: Una experiencia hospitalaria. Málaga, Aljibe.

GOETZ, J.P. y LECOMPTE, M.D. (1988): Etnografía y diseño cualitativo en investigación educativa. Madrid, Morata.

HOLSTI, O.R. (1969): Content analysis for the social sciences and bumanities.MA, Reading Addison-Wesley.

KRIPPENDORF, K. (1990): Metodología de análisis de contenido. Teoría y práctica. Barcelona, Paidós.

LEVI, P. (1986): I sommersi e $i$ salvati. Turín, Einaudi.

NAVARRO, V. (2002): Bienestar insuficiente, democracia incompleta. Sobre lo que no se babla en nuestro país. Barcelona, Anagrama. 
RODRÍGUEZ GONZÁLEZ, J. (2003): León bajo la dictadura franquista (19361951). León, Universidad de León.

RODRIGO, J. (2006): La Guerra Civil: "Memoria", "Olvido", "Recuperación" e "Instrumentación", en Hispania Nova Revista de Historia Contemporánea N.6. [Consultado el 1 de abril de 2010 en http://hispanianova.rediris. es/6/dossier/6d025.pdf].

RUIZ-VARGAS, J.M. (2006): “Trauma y memoria de la Guerra Civil y de la dictadura franquista", en Hispania Nova Revista de Historia Contemporánea N. 6. [Consultado el 19 de abril de 2010 en http://hispanianova.rediris. es/6/dossier/6d012.pdf].

RUIZ TORRES, P.M. (2007): "Los discursos de la memoria histórica en España", en Hispania Nova Revista de historia contemporánea, N. 7 [Consultado el 12 de abril de 2010 en http:/ / hispanianova.rediris.es/7/ dossier/07d001.pdf].

SEVILLANO, F. (2003): La construcción de la memoria y el olvido en la España democrática. Ayer.

TERRADILLOS BASOCO, J.M. (2010): "La revisión del pasado y la Ley de Memoria Histórica", en Revista penal, N. 25.

TODOROV, T. (2002): Memoria del mal, tentación del bien. Indagación sobre el siglo XX. Barcelona, Península.

VAN DIJK, Teun A. (1997): Racismo y análisis crítico de los medios. Barcelona, Paidós.

VAN MAANEN, J. (1983): Qualitative methodology. Beverly Hills, CA, Sage Publications.

VELASCO, M. y DÍAZ DE RADA, A. (1997): La lógica de la investigación etnográfica. Madrid: Nona.

VILARÓS, T. M. (1998): El mono del desencanto. Una crítica cultural de la transición española (1973-1993). Madrid, Siglo XXI.

VINYES, R. (Coord.). (2004): Un futuro para el pasado. arcelona, CEFID.

DÍEZ GUTIÉRREZ, Enrique Javier. (2011): “Análisis de los textos escolares de historia. Estudio de caso sobre la posguerra civil española" en: Revista Historia de la Educación Latinoamericana N.

16, Tunja, Universidad Pedagógica y Tecnológica de Colombia, RUDECOLOMBIA, SHELA- HISULA pp. 87-118 